\title{
Coupled common fixed point theorems for generalized nonlinear contraction mappings with the mixed monotone property in partially ordered metric spaces
}

\author{
Jong Kyu Kim ${ }^{1 *}$ and Sumit Chandok²
}

"Correspondence:

jongkyuk@kyungnam.ac.kr

${ }^{1}$ Department of Mathematics

Education, Kyungnam University,

Changwon, 631-701, Korea

Full list of author information is

available at the end of the article

\begin{abstract}
The purpose of this paper is to establish some coupled coincidence point theorems for generalized nonlinear contraction mappings with the mixed $g$-monotone property in the framework of metric spaces endowed with partial order. The theorems presented in this paper are generalizations and improvements of the several well-known results in the literature.

MSC: 46N40; 47H10; 54H25; 46T99
\end{abstract}

Keywords: coupled fixed point; ordered metric spaces; mixed monotone property; coupled coincidence point

\section{Introduction and preliminaries}

The Banach contraction principle is one of very popular tools in solving the existence in many problems of mathematical analysis. Due to its simplicity and usefulness, there are a lot of generalizations of this principle in the literature. Ran and Reurings [1] extended the Banach contraction principle in partially ordered sets with some applications to linear and nonlinear matrix equations. While Nieto and López [2] extended the result of Ran and Reurings and applied their main theorems to obtain a unique solution for a first-order ordinary differential equation with periodic boundary conditions. Bhaskar and Lakshmikantham [3] introduced the concept of mixed monotone mappings and obtained some coupled fixed point results. Also, they applied their results to a first-order differential equation with periodic boundary conditions. Recently, many researchers have obtained fixed point, common fixed point, coupled fixed point and coupled common fixed point results in cone metric spaces, partially ordered metric spaces and others (see [1-27]).

Definition 1 Let $(X, d)$ be a metric space and $F: X \times X \rightarrow X$ and $g: X \rightarrow X, F$ and $g$ are said to commute if $F(g x, g y)=g(F(x, y))$ for all $x, y \in X$.

Definition 2 Let $(X, \preceq)$ be a partially ordered set and $F: X \times X \rightarrow X$. The mapping $F$ is said to be non-decreasing if for $x, y \in X, x \preceq y$ implies $F(x) \preceq F(y)$ and non-increasing if for $x, y \in X, x \preceq y$ implies $F(x) \succeq F(y)$.

○2013 Kim and Chandok; licensee Springer. This is an Open Access article distributed under the terms of the Creative Commons Attribution License (http://creativecommons.org/licenses/by/2.0), which permits unrestricted use, distribution, and reproduction in any medium, provided the original work is properly cited. 
Definition 3 Let $(X, \preceq)$ be a partially ordered set and $F: X \times X \rightarrow X$ and $g: X \rightarrow X$. The mapping $F$ is said to have the mixed $g$-monotone property if $F(x, y)$ is monotone $g$-nondecreasing in $x$ and monotone $g$-non-increasing in $y$, that is, for any $x, y \in X$,

$$
x_{1}, x_{2} \in X, \quad g x_{1} \preceq g x_{2} \quad \Rightarrow \quad F\left(x_{1}, y\right) \preceq F\left(x_{2}, y\right),
$$

and

$$
y_{1}, y_{2} \in X, \quad g y_{1} \preceq g y_{2} \quad \Rightarrow \quad F\left(x, y_{1}\right) \succeq F\left(x, y_{2}\right) .
$$

If $g=$ identity mapping in Definition 3, then the mapping $F$ is said to have the mixed monotone property.

Definition 4 An element $(x, y) \in X \times X$ is called a coupled coincidence point of the mappings $F: X \times X \rightarrow X$ and $g: X \rightarrow X$ if $F(x, y)=g x$ and $F(y, x)=g y$.

If $g$ is the identity mapping in Definition 4 , then $(x, y) \in X \times X$ is called a coupled fixed point.

Geraghty [16] introduced an extension of the Banach contraction principle in which the contraction constant was replaced by a function having some specified properties.

Definition 5 Let $\Theta$ be the class of functions $\beta: \mathbb{R}^{+} \rightarrow[0,1)$ with

(i) $\mathbb{R}^{+}=\{\mathbb{R} / t>0\}$;

(ii) $\beta\left(t_{n}\right) \rightarrow 1$ implies $t_{n} \rightarrow 0$.

The method applied by Geraghty [16] was utilized to obtain further new fixed point result works like $[6,7,15]$.

The purpose of this paper is to establish some coupled coincidence point results for a pair of mappings with the mixed $g$-monotone property satisfying a generalized contractive condition by using the ideas of Geraghty [16] in partially ordered metric spaces. Also we give some examples to illustrate the main results.

\section{Main results}

Theorem 6 Let $(X, \preceq)$ be a partially ordered set and suppose that there exists a metric d on $X$ such that $(X, d)$ is a complete metric space. Suppose that $F: X \times X \rightarrow X$ and $g: X \rightarrow X$ are self-mappings on $X$ such that $F$ has the mixed g-monotone property on $X$ such that there exist two elements $x_{0}, y_{0} \in X$ with $g\left(x_{0}\right) \preceq F\left(x_{0}, y_{0}\right)$ and $g\left(y_{0}\right) \succeq F\left(y_{0}, x_{0}\right)$. Suppose that there exists $\theta \in \Theta$ such that

$$
d(F(x, y), F(u, v)) \leq \theta\left(\frac{d(g x, g u)+d(g y, g v)}{2}\right)\left(\frac{d(g x, g u)+d(g y, g v)}{2}\right)
$$

for all $x, y, u, v \in X$ with $g x \succeq g u$ and $g y \preceq g v$. Further suppose that $F(X \times X) \subseteq g(X), g$ is continuous and commutes with $F$, and also suppose that either

(a) $F$ is continuous, or

(b) $X$ has the following properties:

(i) if $\left\{g\left(x_{n}\right)\right\} \subset X$ is a non-decreasing sequence with $g x_{n} \rightarrow g x$ in $g(X)$, then $g x_{n} \preceq g x$ for every $n$; 
(ii) if $\left\{g\left(y_{n}\right)\right\} \subset X$ is a non-increasing sequence with $g y_{n} \rightarrow g y$ in $g(X)$, then $g y_{n} \succeq g y$ for every $n$.

Then there exist two elements $x, y \in X$ such that $F(x, y)=g(x)$ and $g y=F(y, x)$, that is, $F$ and $g$ have a coupled coincidence point $(x, y) \in X \times X$.

Proof Let $x_{0}, y_{0} \in X$ be such that $g x_{0} \preceq F\left(x_{0}, y_{0}\right)$ and $g y_{0} \succeq F\left(y_{0}, x_{0}\right)$. Since $F(X \times X) \subseteq$ $g(X)$, we can construct sequences $\left\{x_{n}\right\}$ and $\left\{y_{n}\right\}$ in $X$ such that

$$
g x_{n+1}=F\left(x_{n}, y_{n}\right) \quad \text { and } \quad g y_{n+1}=F\left(y_{n}, x_{n}\right), \quad \forall n \geq 0
$$

We claim that for all $n \geq 0$,

$$
g x_{n} \preceq g x_{n+1},
$$

and

$$
g y_{n} \succeq g y_{n+1} \text {. }
$$

We use the mathematical induction. Let $n=0$. Since $g x_{0} \preceq F\left(x_{0}, y_{0}\right)$ and $g y_{0} \succeq F\left(y_{0}, x_{0}\right)$, in view of $g x_{1}=F\left(x_{0}, y_{0}\right)$ and $g y_{1}=F\left(y_{0}, x_{0}\right)$, we have $g x_{0} \preceq g x_{1}$ and $g y_{0} \succeq g y_{1}$, that is, (2.3) and (2.4) hold for $n=0$. Suppose that (2.3) and (2.4) hold for some $n>0$. As $F$ has the mixed $g$-monotone property and $g x_{n} \preceq g x_{n+1}$ and $g y_{n} \succeq g y_{n+1}$, from (2.2), we get

$$
g x_{n+1}=F\left(x_{n}, y_{n}\right) \preceq F\left(x_{n+1}, y_{n}\right) \preceq F\left(x_{n+1}, y_{n+1}\right)=g x_{n+2}
$$

and

$$
g y_{n+1}=F\left(y_{n}, x_{n}\right) \succeq F\left(y_{n+1}, x_{n}\right) \succeq F\left(y_{n+1}, x_{n+1}\right)=g y_{n+2} .
$$

Now from (2.5) and (2.6), we obtain that $g x_{n+1} \preceq g x_{n+2}$ and $g y_{n+1} \succeq g y_{n+2}$. Thus, by the mathematical induction, we conclude that (2.3) and (2.4) hold for all $n \geq 0$. Therefore

$$
g x_{0} \preceq g x_{1} \preceq g x_{2} \preceq \cdots \preceq g x_{n} \preceq g x_{n+1} \preceq \cdots
$$

and

$$
g y_{0} \succeq g y_{1} \succeq g y_{2} \succeq \cdots \succeq g y_{n} \succeq g y_{n+1} \succeq \cdots
$$

Assume that there is some $r \in \mathbb{N}$ such that $d\left(g x_{r}, g x_{r-1}\right)+d\left(g y_{r}, g y_{r-1}\right)=0$, that is, $g x_{r}=$ $g x_{r-1}$ and $g y_{r}=g y_{r-1}$. Then $g x_{r-1}=F\left(x_{r-1}, y_{r-1}\right)$ and $g y_{r-1}=F\left(y_{r-1}, x_{r-1}\right)$, and hence we get the result.

For simplicity, let $t_{n+1}:=d\left(g x_{n+1}, g x_{n}\right)+d\left(g y_{n+1}, g y_{n}\right)$. Now, we assume that

$$
t_{n}=d\left(g x_{n}, g x_{n-1}\right)+d\left(g y_{n}, g y_{n-1}\right) \neq 0
$$


for all $n$. Since $g x_{n} \succeq g x_{n-1}$ and $g y_{n} \preceq g y_{n-1}$, from (2.1) and (2.2), we have

$$
\begin{aligned}
t_{n+1}= & d\left(g x_{n+1}, g x_{n}\right)+d\left(g y_{n+1}, g y_{n}\right) \\
= & d\left(F\left(x_{n}, y_{n}\right), F\left(x_{n-1}, y_{n-1}\right)\right)+d\left(F\left(y_{n}, x_{n}\right), F\left(y_{n-1}, x_{n-1}\right)\right) \\
\leq & \theta\left(\frac{d\left(g x_{n-1}, g x_{n}\right)+d\left(g y_{n-1}, g y_{n}\right)}{2}\right)\left(\frac{d\left(g x_{n-1}, g x_{n}\right)+d\left(g y_{n-1}, g y_{n}\right)}{2}\right) \\
& +\theta\left(\frac{d\left(g x_{n-1}, g x_{n}\right)+d\left(g y_{n-1}, g y_{n}\right)}{2}\right)\left(\frac{d\left(g x_{n-1}, g x_{n}\right)+d\left(g y_{n-1}, g y_{n}\right)}{2}\right) \\
= & \theta\left(\frac{d\left(g x_{n-1}, g x_{n}\right)+d\left(g y_{n-1}, g y_{n}\right)}{2}\right)\left(d\left(g x_{n-1}, g x_{n}\right)+d\left(g y_{n-1}, g y_{n}\right)\right) \\
= & \theta\left(\frac{d\left(g x_{n-1}, g x_{n}\right)+d\left(g y_{n-1}, g y_{n}\right)}{2}\right)\left(t_{n}\right) \\
\leq & t_{n},
\end{aligned}
$$

which implies that $t_{n+1} \leq t_{n}$. It follows that $\left\{t_{n}\right\}$ is a monotone decreasing sequence of nonnegative real numbers. Therefore, there is some $t \geq 0$ such that $\lim _{n \rightarrow \infty} t_{n}=t$.

Now, we show that $t=0$. Assume to the contrary that $t>0$, then from (2.9) we have

$$
\frac{t_{n+1}}{t_{n}} \leq \theta\left(\frac{d\left(g x_{n-1}, g x_{n}\right)+d\left(g y_{n-1}, g y_{n}\right)}{2}\right)<1,
$$

which yields that $\lim _{n \rightarrow \infty} \theta\left(\frac{t_{n}}{2}\right)=1$. This implies that $d\left(g x_{n-1}, g x_{n}\right) \rightarrow 0$ and $d\left(g y_{n-1}\right.$, $\left.g y_{n}\right) \rightarrow 0$. Therefore $t=0$, that is,

$$
\lim _{n \rightarrow \infty} t_{n}=\lim _{n \rightarrow \infty}\left[d\left(g x_{n+1}, g x_{n}\right)+d\left(g y_{n+1}, g y_{n}\right)\right]=0 .
$$

Next, we prove that $\left\{g x_{n}\right\}$ and $\left\{g y_{n}\right\}$ are Cauchy sequences. On the contrary, assume that at least one of $\left\{g x_{n}\right\}$ or $\left\{g y_{n}\right\}$ is not a Cauchy sequence. Then there exists an $\epsilon>0$ for which we can find subsequences $\left\{g x_{m(k)}\right\}$ and $\left\{g x_{n(k)}\right\}$ of $\left\{g x_{n}\right\}$, and $\left\{g y_{m(k)}\right\}$ and $\left\{g y_{n(k)}\right\}$ of $\left\{g y_{n}\right\}$ with $n(k)>m(k)>k$ such that for every $k$,

$$
d\left(g x_{m(k)}, g x_{n(k)}\right)+d\left(g y_{m(k)}, g y_{n(k)}\right) \geq \epsilon .
$$

Further, corresponding to $m(k)$, we can choose $n(k)$ in such a way that it is the smallest integer with $n(k)>m(k) \geq k$ and satisfies (2.11). Then

$$
d\left(g x_{n(k)-1}, g x_{m(k)}\right)+d\left(g y_{n(k)-1}, g y_{m(k)}\right)<\epsilon .
$$

Using (2.11) and (2.12), we have

$$
\begin{aligned}
\epsilon \leq & r_{k}:=d\left(g x_{n(k)}, g x_{m(k)}\right)+d\left(g y_{n(k)}, g y_{m(k)}\right) \\
\leq & d\left(g x_{n(k)}, g x_{n(k)-1}\right)+d\left(g x_{n(k)-1}, g x_{m(k)}\right) \\
& +d\left(g y_{n(k)}, g y_{n(k)-1}\right)+d\left(g y_{n(k)-1}, g y_{m(k)}\right) \\
< & \epsilon+t_{n(k)} .
\end{aligned}
$$


Letting $k \rightarrow \infty$ and using (2.10), we have

$$
\lim r_{k}=\lim \left[d\left(g x_{m(k)}, g x_{n(k)}\right)+d\left(g y_{m(k)}, g y_{n(k)}\right)\right]=\epsilon .
$$

Also, by the triangle inequality, we have

$$
\begin{aligned}
r_{k}= & d\left(g x_{n(k)}, g x_{m(k)}\right)+d\left(g y_{n(k)}, g y_{m(k)}\right) \\
\leq & d\left(g x_{n(k)}, g x_{n(k)+1}\right)+d\left(g x_{n(k)+1}, g x_{m(k)+1}\right)+d\left(g x_{m(k)+1}, g x_{m(k)}\right) \\
& +d\left(g y_{n(k)}, g y_{n(k)+1}\right)+d\left(g y_{n(k)+1}, g y_{m(k)+1}\right)+d\left(g y_{m(k)+1}, g y_{m(k)}\right) \\
= & t_{n(k)}+t_{m(k)}+d\left(g x_{n(k)+1}, g x_{m(k)+1}\right)+d\left(g y_{n(k)+1}, g x_{m(k)+1}\right) .
\end{aligned}
$$

Since $n(k)>m(k), g x_{n(k)} \succeq g x_{m(k)}$ and $g y_{n(k)} \preceq g y_{m(k)}$, from (2.1) and (2.2), we have

$$
\begin{aligned}
& d\left(g x_{n(k)+1}, g x_{m(k)+1}\right)+d\left(g y_{n(k)+1}, g y_{m(k)+1}\right) \\
& =d\left(F\left(x_{n(k)}, y_{n(k)}\right), F\left(x_{m(k)}, y_{m(k)}\right)\right) \\
& \quad+d\left(F\left(y_{n(k)}, x_{n(k)}\right), F\left(y_{m(k)}, x_{m(k)}\right)\right) \\
& \leq \theta\left(\frac{d\left(g x_{n(k)}, g x_{m(k)}\right)+d\left(g y_{n(k)}, g y_{m(k)}\right)}{2}\right) \\
& \quad \times\left(d\left(g x_{n(k)}, g x_{m(k)}\right)+d\left(g y_{n(k)}, g y_{m(k)}\right)\right) \\
& =\theta\left(\frac{d\left(g x_{n(k)}, g x_{m(k)}\right)+d\left(g y_{n(k)}, g y_{m(k)}\right)}{2}\right) r_{k} .
\end{aligned}
$$

Therefore, we have

$$
r_{k} \leq t_{n(k)}+t_{m(k)}+\theta\left(\frac{d\left(g x_{n(k)}, g x_{m(k)}\right)+d\left(g y_{n(k)}, g y_{m(k)}\right)}{2}\right) r_{k} .
$$

This implies that

$$
\frac{r_{k}-t_{n(k)}-t_{m(k)}}{r_{k}} \leq \theta\left(\frac{d\left(g x_{n(k)}, g x_{m(k)}\right)+d\left(g y_{n(k)}, g y_{m(k)}\right)}{2}\right)<1 .
$$

Taking $k \rightarrow \infty$, we get

$$
\theta\left(\frac{d\left(g x_{n(k)}, g x_{m(k)}\right)+d\left(g y_{n(k)}, g y_{m(k)}\right)}{2}\right)=1 .
$$

Since $\theta \in \Theta$, we get

$$
\lim _{n \rightarrow \infty} d\left(g x_{n(k)}, g x_{m(k)}\right)=\lim _{n \rightarrow \infty} d\left(g y_{n(k)}, g y_{m(k)}\right)=0,
$$

which is a contradiction. This implies that $\left\{g x_{n}\right\}$ and $\left\{g y_{n}\right\}$ are Cauchy sequences in $X$. Since $X$ is a complete metric space, there is $(x, y) \in X \times X$ such that $g x_{n} \rightarrow x$ and $g y_{n} \rightarrow y$. Since $g$ is continuous, $g\left(g x_{n}\right) \rightarrow g x$ and $g\left(g y_{n}\right) \rightarrow g y$.

First, suppose that $F$ is continuous. Then $F\left(g x_{n}, g y_{n}\right) \rightarrow F(x, y)$ and $F\left(g y_{n}, g x_{n}\right) \rightarrow F(y, x)$. As $F$ commutes with $g$, we have $F\left(g x_{n}, g y_{n}\right)=g F\left(x_{n}, y_{n}\right)=g\left(g x_{n+1}\right) \rightarrow g x$ and $F\left(g y_{n}, g x_{n}\right)=$ 
$g F\left(y_{n}, x_{n}\right)=g\left(g y_{n+1}\right) \rightarrow g y$. By the uniqueness of the limit, we get $g x=F(x, y)$ and $g y=$ $F(y, x)$.

Second, suppose that (b) holds. Since $\left\{g x_{n}\right\}$ is a non-decreasing sequence such that $g x_{n} \rightarrow x$ and $\left\{g y_{n}\right\}$ is a non-increasing sequence such that $g y_{n} \rightarrow y$, and $g$ is a nonincreasing function, we get $g\left(g x_{n}\right) \preceq g x$ and $g\left(g y_{n}\right) \succeq g y$ hold for all $n \in \mathbb{N}$. Hence, by (2.1), we have

$$
\begin{aligned}
& d\left(g\left(g x_{n+1}\right), F(x, y)\right)+d\left(g\left(g y_{n+1}\right), F(y, x)\right) \\
& \quad=d\left(F\left(g x_{n}, g y_{n}\right), F(x, y)\right)+d\left(F\left(g y_{n}, g x_{n}\right) F(y, x)\right) \\
& \quad \leq \theta\left(\frac{d\left(g\left(g x_{n}\right), g x\right)+d\left(g\left(g y_{n}\right), g y\right)}{2}\right)\left(d\left(g\left(g x_{n}\right), g x\right)+d\left(g\left(g y_{n}\right), g y\right)\right) .
\end{aligned}
$$

Taking $n \rightarrow \infty$, we get $d(g x+F(x, y))+d(g y, F(y, x))=0$, and hence $g x=F(x, y)$ and $g y=$ $F(y, x)$. Thus $F$ and $g$ have a coupled coincidence point.

If $\theta(t)=k$, where $k \in[0,1)$, then we have the following result.

Corollary 7 Let $(X, \preceq)$ be a partially ordered set and suppose that there exists a metric $d$ on $X$ such that $(X, d)$ is a complete metric space. Suppose that $F: X \times X \rightarrow X$ and $g: X \rightarrow X$ are self-mappings on $X$ such that $F$ has the mixed $g$-monotone property on $X$ such that there exist two elements $x_{0}, y_{0} \in X$ with $g\left(x_{0}\right) \preceq F\left(x_{0}, y_{0}\right)$ and $g\left(y_{0}\right) \succeq F\left(y_{0}, x_{0}\right)$. Suppose that there exists $k \in[0,1)$ such that

$$
d(F(x, y), F(u, v)) \leq k\left(\frac{d(g x, g u)+d(g y, g v)}{2}\right)
$$

satisfies for all $x, y, u, v \in X$ with $g x \succeq$ gu and $g y \preceq$ gv. Further suppose that $F(X \times X) \subseteq g(X)$, $g$ is continuous non-decreasing and commutes with $F$ and also suppose that either

(a) $F$ is continuous, or

(b) $X$ has the following properties:

(i) if $\left\{g\left(x_{n}\right)\right\} \subset X$ is a non-decreasing sequence with $g x_{n} \rightarrow g x$ in $g(X)$, then $g x_{n} \preceq g x$ for every $n$;

(ii) if $\left\{g\left(y_{n}\right)\right\} \subset X$ is a non-increasing sequence with $g y_{n} \rightarrow g y$ in $g(X)$, then $g y_{n} \succeq g y$ for every $n$.

Then there exist two elements $x, y \in X$ such that $F(x, y)=g(x)$ and $g y=F(y, x)$, that is, $F$ and $g$ have a coupled coincidence point $(x, y) \in X \times X$.

If $g$ is an identity mapping, we have the following result of Bhaskar and Lakshmikantham [3].

Corollary 8 Let $(X, \preceq)$ be a partially ordered set and suppose that there exists a metric $d$ on $X$ such that $(X, d)$ is a metric space. Suppose that $F: X \times X \rightarrow X$ is a mapping on $X$ and has the mixed monotone property on $X$ such that there exist two elements $x_{0}, y_{0} \in X$ with $x_{0} \preceq F\left(x_{0}, y_{0}\right)$ and $y_{0} \succeq F\left(y_{0}, x_{0}\right)$. Suppose that there exists $k \in[0,1)$ such that

$$
d(F(x, y), F(u, v)) \leq \frac{k}{2}(d(x, u)+d(y, v))
$$

for all $x, y, u, v \in X$ with $x \succeq u$ and $y \preceq v$. Further suppose that either 
(a) $F$ is continuous, or

(b) $X$ has the following properties:

(i) if $\left\{x_{n}\right\} \subset X$ is a non-decreasing sequence with $x_{n} \rightarrow x$ in $X$, then $x_{n} \preceq x$ for each $n \geq 1$

(ii) if $\left\{y_{n}\right\} \subset X$ is a non-increasing sequence with $y_{n} \rightarrow y$ in $X$, then $y_{n} \succeq y$ for each $n \geq 1$.

Then there exist two elements $x, y \in X$ such that $F(x, y)=x$ and $y=F(y, x)$, that is, $F$ has a coupled fixed point $(x, y) \in X \times X$.

Example 9 Let $X=[0,1]$. Then $(X, \leq)$ is a partially ordered set with the natural ordering of real numbers. Let $d(x, y)=|x-y|$ for all $x, y \in X$. Define a mapping $g: X \rightarrow X$ by $g(x)=x$ and a mapping $F: X \times X \rightarrow X$ by

$$
F(x, y)= \begin{cases}\frac{x-y}{4}, & x \geq y ; \\ 0, & x<y .\end{cases}
$$

Then it is easy to prove that $(X, d)$ is a complete metric space, $g(X)$ is complete, $F: X \times X \rightarrow$ $X \subseteq g(X)=X, X$ satisfies conditions (1) and (2) of Theorem 6 and $F$ has the $g$-monotone property. Let $\theta:(0, \infty) \rightarrow[0,1)$ be defined by

$$
\theta(t)= \begin{cases}1-\frac{t}{2}, & t \leq 1 ; \\ \alpha<1, & t>1 .\end{cases}
$$

Now, we verify the inequality (2.1) of Theorem 6 for all $x, y, u, v \in X$ with $g x \geq g u$ and $g y \preceq g v$.

Now, we consider the following cases.

Case 1. $(x, y)=(0,0),(u, v)=(0,1)$ or $(x, y)=(1,1),(u, v)=(0,1)$, we have

$$
d(F(x, y), F(u, v))=0 .
$$

Hence inequality (2.1) holds.

Case 2. $(x, y)=(1,0),(u, v)=(0,0)$, we have

$$
d(F(x, y), F(u, v))=d(F(1,0), F(0,0))=\frac{1}{4}
$$

and

$$
\begin{aligned}
& \theta\left(\frac{d(g x, g u)+d(g y, g v)}{2}\right)\left(\frac{d(g x, g u)+d(g y, g v)}{2}\right) \\
& \quad=\theta\left(\frac{d(1,0)+d(0,0)}{2}\right)\left(\frac{d(1,0)+d(0,0)}{2}\right) \\
& \quad=\theta\left(\frac{1}{2}\right)\left(\frac{1}{2}\right) \\
& \quad=\left(1-\frac{1}{4}\right) \frac{1}{2} .
\end{aligned}
$$

Hence inequality (2.1) holds. 
Case 3. $(x, y)=(1,0),(u, v)=(0,1)$, we have

$$
d(F(x, y), F(u, v))=d(F(1,0), F(0,1))=\frac{1}{4}
$$

and

$$
\begin{aligned}
& \theta\left(\frac{d(g x, g u)+d(g y, g v)}{2}\right)\left(\frac{d(g x, g u)+d(g y, g v)}{2}\right) \\
& \quad=\theta\left(\frac{d(1,0)+d(0,1)}{2}\right)\left(\frac{d(1,0)+d(0,1)}{2}\right) \\
& \quad=\theta(1)(1) \\
& \quad=\left(1-\frac{1}{2}\right) .
\end{aligned}
$$

Hence inequality (2.1) holds.

Case 4. $(x, y)=(1,0),(u, v)=(1,1)$, we have

$$
d(F(x, y), F(u, v))=d(F(1,0), F(1,1))=\frac{1}{4}
$$

and

$$
\begin{aligned}
& \theta\left(\frac{d(g x, g u)+d(g y, g v)}{2}\right)\left(\frac{d(g x, g u)+d(g y, g v)}{2}\right) \\
& \quad=\theta\left(\frac{d(1,1)+d(0,1)}{2}\right)\left(\frac{d(1,1)+d(0,1)}{2}\right) \\
& \quad=\theta\left(\frac{1}{2}\right)\left(\frac{1}{2}\right) \\
& \quad=\left(1-\frac{1}{4}\right) \frac{1}{2} .
\end{aligned}
$$

Hence inequality (2.1) holds.

Thus, in all the cases, inequality (2.1) of Theorem 6 is satisfied. Hence, by Theorem 6, $(0,0)$ is a coupled coincidence point of $F$ and $g$.

Theorem 10 Let $(X, \preceq)$ be a partially ordered set and suppose that there exists a metric $d$ on $X$ such that $(X, d)$ is a complete metric space. Suppose that $F: X \times X \rightarrow X$ and $g: X \rightarrow X$ are self-mappings on $X$ such that $F$ has the mixed $g$-monotone property on $X$ such that there exist two elements $x_{0}, y_{0} \in X$ with $g\left(x_{0}\right) \preceq F\left(x_{0}, y_{0}\right)$ and $g\left(y_{0}\right) \succeq F\left(y_{0}, x_{0}\right)$. Suppose that there exists $\theta \in \Theta$ such that

$$
d(F(x, y), F(u, v)) \leq \theta(M(x, y, u, v))(M(x, y, u, v)),
$$

where

$$
M(x, y, u, v)=\frac{d(g x, F(x, y))+d(g y, F(y, x))+d(g u, F(u, v))+d(g v, F(v, u))}{4}
$$


for all $x, y, u, v \in X$ with $g x \geq g u$ and $g y \preceq g v$. Further suppose that $F(X \times X) \subseteq g(X), g$ is continuous non-decreasing and commutes with $F$ and also suppose that either

(a) $F$ is continuous, or

(b) $X$ has the following properties:

(i) if $\left\{g\left(x_{n}\right)\right\} \subset X$ is a non-decreasing sequence with $g x_{n} \rightarrow g x$ in $g(X)$, then $g x_{n} \preceq g x$ for every $n$;

(ii) if $\left\{g\left(y_{n}\right)\right\} \subset X$ is a non-increasing sequence with $g y_{n} \rightarrow g y$ in $g(X)$, then $g y_{n} \succeq g y$ for every $n$.

Then there exist two elements $x, y \in X$ such that $F(x, y)=g(x)$ and $g y=F(y, x)$, that is, $F$ and $g$ have a coupled coincidence point $(x, y) \in X \times X$.

Proof Following the proof of Theorem 6, we have an increasing sequence $\left\{x_{n}\right\}$ and a decreasing sequence $\left\{y_{n}\right\}$ in $X$. Now, we assume that

$$
t_{n}=d\left(g x_{n}, g x_{n-1}\right)+d\left(g y_{n}, g y_{n-1}\right) \neq 0
$$

for all $n$.

Since $g x_{n} \succeq g x_{n-1}$ and $g y_{n} \preceq g y_{n-1}$, from (2.16) and (2.2), we have

$$
\begin{aligned}
t_{n+1}= & d\left(g x_{n+1}, g x_{n}\right)+d\left(g y_{n+1}, g y_{n}\right) \\
= & d\left(F\left(x_{n}, y_{n}\right), F\left(x_{n-1}, y_{n-1}\right)\right)+d\left(F\left(y_{n}, x_{n}\right), F\left(y_{n-1}, x_{n-1}\right)\right) \\
\leq & \theta\left(\frac{d\left(g x_{n}, F\left(x_{n}, y_{n}\right)\right)+d\left(g y_{n}, F\left(y_{n}, x_{n}\right)\right)+d\left(g x_{n-1}, F\left(x_{n-1}, y_{n-1}\right)\right)+d\left(g y_{n-1}, F\left(y_{n-1}, x_{n-1}\right)\right)}{4}\right) \\
& \times\left(\frac{d\left(g x_{n}, F\left(x_{n}, y_{n}\right)\right)+d\left(g y_{n}, F\left(y_{n}, x_{n}\right)\right)+d\left(g x_{n-1}, F\left(x_{n-1}, y_{n-1}\right)\right)+d\left(g y_{n-1}, F\left(y_{n-1}, x_{n-1}\right)\right)}{4}\right) \\
& +\theta\left(\frac{d\left(g y_{n}, F\left(y_{n}, x_{n}\right)\right)+d\left(g x_{n}, F\left(x_{n}, y_{n}\right)\right)+d\left(g y_{n-1}, F\left(y_{n-1}, x_{n-1}\right)\right)+d\left(g x_{n-1}, F\left(x_{n-1}, y_{n-1}\right)\right)}{4}\right) \\
& \times\left(\frac{d\left(g y_{n}, F\left(y_{n}, x_{n}\right)\right)+d\left(g x_{n}, F\left(x_{n}, y_{n}\right)\right)+d\left(g y_{n-1}, F\left(y_{n-1}, x_{n-1}\right)\right)+d\left(g x_{n-1}, F\left(x_{n-1}, y_{n-1}\right)\right)}{4}\right) \\
= & \theta\left(\frac{d\left(g x_{n}, F\left(x_{n}, y_{n}\right)\right)+d\left(g y_{n}, F\left(y_{n}, x_{n}\right)\right)+d\left(g x_{n-1}, F\left(x_{n-1}, y_{n-1}\right)\right)+d\left(g y_{n-1}, F\left(y_{n-1}, x_{n-1}\right)\right)}{4}\right) \\
& \times\left(\frac{d\left(g x_{n}, F\left(x_{n}, y_{n}\right)\right)+d\left(g y_{n}, F\left(y_{n}, x_{n}\right)\right)+d\left(g x_{n-1}, F\left(x_{n-1}, y_{n-1}\right)\right)+d\left(g y_{n-1}, F\left(y_{n-1}, x_{n-1}\right)\right)}{2}\right) \\
= & \theta\left(\frac{t_{n}+t_{n+1}}{4}\right)\left(\frac{t_{n}+t_{n+1}}{2}\right) \\
\leq & t_{n} .
\end{aligned}
$$

It follows that $\left\{t_{n}\right\}$ is a monotone decreasing sequence of non-negative real numbers. Therefore, there is some $t \geq 0$ such that $\lim _{n \rightarrow \infty} t_{n}=t$.

Next, we show that $t=0$. Assume to the contrary that $t>0$, then from (2.17) we have

$$
\frac{t_{n+1}}{\frac{t_{n}+t_{n+1}}{2}} \leq \theta\left(\frac{t_{n}+t_{n+1}}{4}\right)<1
$$

which yields that $\lim _{n \rightarrow \infty} \theta\left(\frac{t_{n}+t_{n+1}}{4}\right)=1$. This implies that $d\left(g x_{n-1}, g x_{n}\right) \rightarrow 0$ and $d\left(g y_{n-1}\right.$, $\left.g y_{n}\right) \rightarrow 0$. Therefore $t=0$, that is,

$$
\lim _{n \rightarrow \infty} t_{n}=\lim _{n \rightarrow \infty}\left[d\left(g x_{n+1}, g x_{n}\right)+d\left(g y_{n+1}, g y_{n}\right)\right]=0 .
$$


Now, we prove that $\left\{g x_{n}\right\}$ and $\left\{g y_{n}\right\}$ are Cauchy sequences. On the contrary, assume that at least one of $\left\{g x_{n}\right\}$ or $\left\{g y_{n}\right\}$ is not a Cauchy sequence. Then there exists an $\epsilon>0$ for which we can find subsequences $\left\{g x_{m(k)}\right\}$ and $\left\{g x_{n(k)}\right\}$ of $\left\{g x_{n}\right\}$ and $\left\{g y_{m(k)}\right\}$ and $\left\{g y_{n(k)}\right\}$ of $\left\{g y_{n}\right\}$ with $n(k)>m(k)>k$ such that for every $k$,

$$
r_{k}=d\left(g x_{m(k)}, g x_{n(k)}\right)+d\left(g y_{m(k)}, g y_{n(k)}\right) \geq \epsilon .
$$

Further, corresponding to $m(k)$, we can choose $n(k)$ in such a way that it is the smallest integer with $n(k)>m(k) \geq k$ and satisfies (2.19). Then

$$
d\left(g x_{n(k)-1}, g x_{m(k)}\right)+d\left(g y_{n(k)-1}, g y_{m(k)}\right)<\epsilon .
$$

Using (2.19) and (2.20), we have

$$
\begin{aligned}
\epsilon \leq & r_{k}:=d\left(g x_{n(k)}, g x_{m(k)}\right)+d\left(g y_{n(k)}, g y_{m(k)}\right) \\
\leq & d\left(g x_{n(k)}, g x_{n(k)-1}\right)+d\left(g x_{n(k)-1}, g x_{m(k)}\right) \\
& +d\left(g y_{n(k)}, g y_{n(k)-1}\right)+d\left(g y_{n(k)-1}, g y_{m(k)}\right) \\
< & \epsilon+t_{n(k)} .
\end{aligned}
$$

Letting $k \rightarrow \infty$ and using (2.18), we have

$$
\lim r_{k}=\lim \left[d\left(g x_{m(k)}, g x_{n(k)}\right)+d\left(g y_{m(k)}, g y_{n(k)}\right)\right]=\epsilon .
$$

Also, by the triangle inequality, we have

$$
\begin{aligned}
r_{k}= & d\left(g x_{n(k)}, g x_{m(k)}\right)+d\left(g y_{n(k)}, g y_{m(k)}\right) \\
\leq & d\left(g x_{n(k)}, g x_{n(k)+1}\right)+d\left(g x_{n(k)+1}, g x_{m(k)+1}\right)+d\left(g x_{m(k)+1}, g x_{m(k)}\right) \\
& +d\left(g y_{n(k)}, g y_{n(k)+1}\right)+d\left(g y_{n(k)+1}, g y_{m(k)+1}\right)+d\left(g y_{m(k)+1}, g y_{m(k)}\right) \\
= & t_{n(k)}+t_{m(k)}+d\left(g x_{n(k)+1}, g x_{m(k)+1}\right)+d\left(g y_{n(k)+1}, g x_{m(k)+1}\right) .
\end{aligned}
$$

Since $n(k)>m(k), g x_{n(k)} \succeq g x_{m(k)}$ and $g y_{n(k)} \preceq g y_{m(k)}$, from (2.16) and (2.2), we have

$$
\begin{aligned}
& d\left(g x_{n(k)+1}, g x_{m(k)+1}\right) \\
&= d\left(F\left(x_{n(k)}, y_{n(k)}\right), F\left(x_{m(k)}, y_{m(k)}\right)\right) \\
& \leq \theta\left(\frac{d\left(g x_{n(k)}, g x_{n(k)+1}\right)+d\left(g y_{n(k)}, g y_{n(k)+1}\right)+d\left(g x_{m(k)}, g x_{m(k)+1}\right)+d\left(g y_{m(k)}, g y_{m(k)+1}\right)}{4}\right) \\
& \quad \times\left(\frac{d\left(g x_{n(k)}, g x_{n(k)+1}\right)+d\left(g y_{n(k)}, g y_{n(k)+1}\right)+d\left(g x_{m(k)}, g x_{m(k)+1}\right)+d\left(g y_{m(k)}, g y_{m(k)+1}\right)}{4}\right),
\end{aligned}
$$

and similarly,

$$
\begin{aligned}
& d\left(g y_{n(k)+1}, g x_{m(k)+1}\right) \\
& \quad=d\left(F\left(y_{n(k)}, x_{n(k)}\right), F\left(y_{m(k)}, x_{m(k)}\right)\right)
\end{aligned}
$$




$$
\begin{aligned}
\leq & \theta\left(\frac{d\left(g x_{n(k)}, g x_{n(k)+1}\right)+d\left(g y_{n(k)}, g y_{n(k)+1}\right)+d\left(g x_{m(k)}, g x_{m(k)+1}\right)+d\left(g y_{m(k)}, g y_{m(k)+1}\right)}{4}\right) \\
& \times\left(\frac{d\left(g x_{n(k)}, g x_{n(k)+1}\right)+d\left(g y_{n(k)}, g y_{n(k)+1}\right)+d\left(g x_{m(k)}, g x_{m(k)+1}\right)+d\left(g y_{m(k)}, g y_{m(k)+1}\right)}{4}\right) .
\end{aligned}
$$

Therefore, we have

$$
\begin{aligned}
r_{k} \leq & t_{n(k)}+t_{m(k)} \\
+ & 2 \theta\left(\frac{d\left(g x_{n(k)}, g x_{n(k)+1}\right)+d\left(g y_{n(k)}, g y_{n(k)+1}\right)+d\left(g x_{m(k)}, g x_{m(k)+1}\right)+d\left(g y_{m(k)}, g y_{m(k)+1}\right)}{4}\right) \\
& \times\left(\frac{d\left(g x_{n(k)}, g x_{n(k)+1}\right)+d\left(g y_{n(k)}, g y_{n(k)+1}\right)+d\left(g x_{m(k)}, g x_{m(k)+1}\right)+d\left(g y_{m(k)}, g y_{m(k)+1}\right)}{4}\right) .
\end{aligned}
$$

Taking $k \rightarrow \infty$, we have $t_{n(k)}, t_{m(k)} \rightarrow 0$, and

$$
\frac{d\left(g x_{n(k)}, g x_{n(k)+1}\right)+d\left(g y_{n(k)}, g y_{n(k)+1}\right)+d\left(g x_{m(k)}, g x_{m(k)+1}\right)+d\left(g y_{m(k)}, g y_{m(k)+1}\right)}{4} \rightarrow 0 .
$$

Hence, we get $r_{k}=\epsilon=0$, which is a contradiction. This implies that $\left\{g x_{n}\right\}$ and $\left\{g y_{n}\right\}$ are Cauchy sequences in $g(X)$.

Since $X$ is a complete metric space, there is $(x, y) \in X \times X$ such that $g x_{n} \rightarrow x$ and $g y_{n} \rightarrow y$. Since $g$ is continuous, $g\left(g x_{n}\right) \rightarrow g x$ and $g\left(g y_{n}\right) \rightarrow g y$.

First, suppose that $F$ is continuous. Then $F\left(g x_{n}, g y_{n}\right) \rightarrow F(x, y)$ and $F\left(g y_{n}, g x_{n}\right) \rightarrow F(y, x)$. As $F$ commutes with $g$, we have

$$
F\left(g x_{n}, g y_{n}\right)=g F\left(x_{n}, y_{n}\right)=g\left(g x_{n+1}\right) \rightarrow g x
$$

and

$$
F\left(g y_{n}, g x_{n}\right)=g F\left(y_{n}, x_{n}\right)=g\left(g y_{n+1}\right) \rightarrow g y \text {. }
$$

By the uniqueness of the limit, we get $g x=F(x, y)$ and $g y=F(y, x)$.

Second, suppose that (b) holds. Since $\left\{g x_{n}\right\}$ is a non-decreasing sequence such that $g x_{n} \rightarrow x$ and $\left\{g y_{n}\right\}$ is a non-increasing sequence such that $g y_{n} \rightarrow y$, and $g$ is a nondecreasing function, we get that $g\left(g x_{n}\right) \preceq g x$ and $g\left(g y_{n}\right) \succeq g y$ hold for all $n \in \mathbb{N}$. Hence, by (2.16), we have

$$
\begin{aligned}
& d(\left.\left(g x_{n+1}\right), F(x, y)\right) \\
&= d\left(F\left(g x_{n}, g y_{n}\right), F(x, y)\right) \\
& \leq \theta\left(\frac{d\left(g\left(g x_{n}\right), F\left(g x_{n}, g y_{n}\right)\right)+d\left(g\left(g y_{n}\right), F\left(g y_{n}, g x_{n}\right)\right)+d(g x, F(x, y))+d(g y, F(y, x))}{4}\right) \\
& \quad \times\left(\frac{d\left(g\left(g x_{n}\right), F\left(g x_{n}, g y_{n}\right)\right)+d\left(g\left(g y_{n}\right), F\left(g y_{n}, g x_{n}\right)\right)+d(g x, F(x, y))+d(g y, F(y, x))}{4}\right) \\
&=\theta\left(\frac{d\left(g\left(g x_{n}\right), g\left(g x_{n+1}\right)\right)+d\left(g\left(g y_{n}\right), g\left(g y_{n+1}\right)\right)+d(g x, F(x, y))+d(g y, F(y, x))}{4}\right) \\
& \quad \times\left(\frac{d\left(g\left(g x_{n}\right), g\left(g x_{n+1}\right)\right)+d\left(g\left(g y_{n}\right), g\left(g y_{n+1}\right)\right)+d(g x, F(x, y))+d(g y, F(y, x))}{4}\right)
\end{aligned}
$$


and

$$
\begin{aligned}
d( & \left.\left(g y_{n+1}\right), F(y, x)\right) \\
= & d\left(F\left(g y_{n}, g x_{n}\right), F(y, x)\right) \\
\leq & \theta\left(\frac{d\left(g\left(g y_{n}\right), F\left(g y_{n}, g x_{n}\right)\right)+d\left(g\left(g x_{n}\right), F\left(g x_{n}, g y_{n}\right)\right)+d(g y, F(y, x))+d(g x, F(x, y))}{4}\right) \\
\quad \times\left(\frac{d\left(g\left(g y_{n}\right), F\left(g y_{n}, g x_{n}\right)\right)+d\left(g\left(g x_{n}\right), F\left(g x_{n}, g y_{n}\right)\right)+d(g y, F(y, x))+d(g x, F(x, y))}{4}\right) & \theta\left(\frac{d\left(g\left(g y_{n}\right), g\left(g y_{n+1}\right)\right)+d\left(g\left(g x_{n}\right), g\left(g x_{n+1}\right)\right)+d(g y, F(y, x))+d(g x, F(x, y))}{4}\right) \\
\quad & \times\left(\frac{d\left(g\left(g y_{n}\right), g\left(g y_{n+1}\right)\right)+d\left(g\left(g x_{n}\right), g\left(g x_{n+1}\right)\right)+d(g y, F(y, x))+d(g x, F(x, y))}{4}\right) .
\end{aligned}
$$

Taking $n \rightarrow \infty$, we get $d(g x+F(x, y))+d(g y, F(y, x))=0$, and hence $g x=F(x, y)$ and $g y=$ $F(y, x)$. Thus $F$ and $g$ have a coupled coincidence point.

Example 11 Let $X=[0,1]$. Then $(X, \leq)$ is a partially ordered set with the natural ordering of real numbers. Let $d(x, y)=|x-y|$ for all $x, y \in X$. Define a mapping $g: X \rightarrow X$ by $g(x)=x$ and a mapping $F: X \times X \rightarrow X$ by

$$
F(x, y)= \begin{cases}\frac{x-y}{16}, & x \geq y \\ 0, & x<y .\end{cases}
$$

Then it is easy to prove that $(X, d)$ is a complete metric space, $g(X)$ is complete, $F: X \times X \rightarrow$ $X \subseteq g(X)=X, X$ satisfies conditions (1) and (2) of Theorem 10 and $F$ has the $g$-monotone property. Let $\theta:(0, \infty) \rightarrow[0,1)$ be defined as

$$
\theta(t)= \begin{cases}1-t, & t \leq 1 \\ \alpha<1, & t>1\end{cases}
$$

Now, we verify inequality (2.16) of Theorem 10 for all $x, y, u, v \in X$ with $g x \succeq g u$ and $g y \preceq g v$.

Now, we consider the following cases.

Case 1. $(x, y)=(0,0),(u, v)=(0,1)$ or $(x, y)=(1,1),(u, v)=(0,1)$, we have

$$
d(F(x, y), F(u, v))=0 .
$$

Hence, inequality (2.16) holds.

Case 2. $(x, y)=(1,0),(u, v)=(0,0)$, we have

$$
d(F(x, y), F(u, v))=d(F(1,0), F(0,0))=\frac{1}{16}
$$


and

$$
\begin{aligned}
\theta( & \left.\frac{d(g x, F(x, y))+d(g y, F(y, x))+d(g u, F(u, v))+d(g v, F(v, u))}{4}\right) \\
& \times\left(\frac{d(g x, F(x, y))+d(g y, F(y, x))+d(g u, F(u, v))+d(g v, F(v, u))}{4}\right) \\
= & \theta\left(\frac{d(1, F(1,0))+d(0, F(0,1))+0+0}{4}\right)\left(\frac{d(1, F(1,0))+d(0, F(0,1))+0+0}{4}\right) \\
= & \theta\left(\frac{15}{64}\right)\left(\frac{15}{64}\right) \\
= & \left(1-\frac{15}{64}\right) \frac{15}{64} .
\end{aligned}
$$

Hence, inequality (2.16) holds.

Case 3. $(x, y)=(1,0),(u, v)=(0,1)$, we have

$$
d(F(x, y), F(u, v))=d(F(1,0), F(0,1))=\frac{1}{16}
$$

and

$$
\begin{aligned}
\theta( & \left.\frac{d(g x, F(x, y))+d(g y, F(y, x))+d(g u, F(u, v))+d(g v, F(v, u))}{4}\right) \\
\quad & \times\left(\frac{d(g x, F(x, y))+d(g y, F(y, x))+d(g u, F(u, v))+d(g v, F(v, u))}{4}\right) \\
= & \theta\left(\frac{d(1, F(1,0))+d(0, F(0,1))+d(0, F(0,1))+d(1, F(1,0))}{4}\right) \\
& \times\left(\frac{d(1, F(1,0))+d(0, F(0,1))+d(0, F(0,1))+d(1, F(1,0))}{4}\right) \\
= & \theta\left(\frac{30}{64}\right)\left(\frac{30}{64}\right) \\
= & \left(1-\frac{30}{64}\right) \frac{30}{64} .
\end{aligned}
$$

Hence, inequality (2.16) holds.

Case 4. $(x, y)=(1,0),(u, v)=(1,1)$, we have

$$
d(F(x, y), F(u, v))=d(F(1,0), F(1,1))=\frac{1}{16} ;
$$

and

$$
\begin{gathered}
\theta\left(\frac{d(g x, F(x, y))+d(g y, F(y, x))+d(g u, F(u, v))+d(g v, F(v, u))}{4}\right) \\
\quad \times\left(\frac{d(g x, F(x, y))+d(g y, F(y, x))+d(g u, F(u, v))+d(g v, F(v, u))}{4}\right) \\
=\theta\left(\frac{d(1, F(1,0))+d(0, F(0,1))+d(1, F(1,1))+d(1, F(1,1))}{4}\right)
\end{gathered}
$$




$$
\begin{aligned}
& \times\left(\frac{d(1, F(1,0))+d(0, F(0,1))+d(1, F(1,1))+d(1, F(1,1))}{4}\right) \\
= & \theta\left(\frac{47}{64}\right)\left(\frac{47}{64}\right) \\
= & \left(1-\frac{47}{64}\right) \frac{47}{64} .
\end{aligned}
$$

Hence, inequality (2.16) holds.

Thus, in all the cases, inequality (2.16) of Theorem 10 is satisfied. Hence, by Theorem 10, $(0,0)$ is a coupled coincidence point of $F$ and $g$.

Next, we prove the existence of a coupled coincidence point theorem, where we do not require that $F$ and $g$ are commuting.

The following lemma proved by Haghi et al. [17] is useful for our results.

Lemma 12 [17] Let $X$ be a nonempty set, and let $g: X \rightarrow X$ be a mapping. Then there exists a subset $E \subseteq X$ such that $g(E)=g(X)$ and $g: E \rightarrow X$ is one-to-one.

Theorem 13 Let $(X, \preceq)$ be a partially ordered set and suppose that there exists a metric $d$ on $X$ such that $(X, d)$ is a metric space. Suppose that $F: X \times X \rightarrow X$ and $g: X \rightarrow X$ are self-mappings on $X$ such that $F$ has the mixed g-monotone property on $X$ such that there exist two elements $x_{0}, y_{0} \in X$ with $g\left(x_{0}\right) \preceq F\left(x_{0}, y_{0}\right)$ and $g\left(y_{0}\right) \succeq F\left(y_{0}, x_{0}\right)$. Suppose that there exists $\theta \in \Theta$ such that

$$
d(F(x, y), F(u, v)) \leq \theta\left(\frac{d(g x, g u)+d(g y, g v)}{2}\right)\left(\frac{d(g x, g u)+d(g y, g v)}{2}\right)
$$

for all $x, y, u, v \in X$ with $g x \succeq g u$ and $g y \preceq g v$. Further suppose that $F(X \times X) \subseteq g(X)$ and $g(X)$ is a complete subspace of $X$. Also assume that either

(a) $F$ is continuous, or

(b) $X$ has the following properties:

(i) if $\left\{g\left(x_{n}\right)\right\} \subset X$ is a non-decreasing sequence with $g x_{n} \rightarrow g x$ in $g(X)$, then $g x_{n} \preceq g x$ for every $n$;

(ii) if $\left\{g\left(y_{n}\right)\right\} \subset X$ is a non-increasing sequence with $g y_{n} \rightarrow g y$ in $g(X)$, then $g y_{n} \succeq g y$ for every $n$.

Then there exist two elements $x, y \in X$ such that $F(x, y)=g(x)$ and $g y=F(y, x)$, that is, $F$ and $g$ have a coupled coincidence point $(x, y) \in X \times X$.

Proof Using Lemma 12, there exists $E \subseteq X$ such that $g(E)=g(X)$ and $g: E \rightarrow X$ is one-toone. We define a mapping $A: g(E) \times g(E) \rightarrow X$ by

$$
A(g x, g y)=F(x, y) \quad \text { for every } g x, g y \in g(E) .
$$

As $g$ is one-to-one on $g(E)$, so $A$ is well defined.

Since $F$ has the mixed $g$-monotone property, for all $x, y \in X$, we have

$$
x_{1}, x_{2} \in X, \quad g x_{1} \preceq g x_{2} \quad \Leftrightarrow \quad F\left(x_{1}, y\right) \preceq F\left(x_{2}, y\right)
$$


and

$$
y_{1}, y_{2} \in X, \quad g y_{1} \succeq g y_{2} \quad \Leftrightarrow \quad F\left(x, y_{1}\right) \succeq F\left(x, y_{2}\right) .
$$

Thus, it follows from (2.23), (2.24) and (2.25) that for all $g x, g y \in g(E)$,

$$
g x_{1}, g x_{2} \in g(E), \quad g x_{1} \preceq g x_{2} \quad \Leftrightarrow \quad A\left(g x_{1}, g y\right) \preceq A\left(g x_{2}, g y\right)
$$

and

$$
g y_{1}, g y_{2} \in g(E), \quad g y_{1} \succeq g y_{2} \quad \Leftrightarrow \quad A\left(g x, g y_{1}\right) \succeq A\left(g x, g y_{2}\right),
$$

which implies that $A$ has the mixed monotone property.

Suppose that the assumption (a) holds. Since $F$ is continuous, $A$ is also continuous. Using Theorem 2.1 of [15] with the mapping $A$, it follows that $A$ has a coupled fixed point $(u, v) \in$ $g(X) \times g(X)$.

Suppose that the assumption (b) holds. We can conclude similarly to the proof of Theorem 2.1 of [15] that the mapping $A$ has a coupled fixed point $(u, v) \in g(X) \times g(X)$.

Finally, we prove that $F$ and $g$ have a coupled coincidence point in $X$. Since $(u, v)$ is a coupled fixed point of $A$, we get

$$
u=A(u, v), \quad v=A(v, u) .
$$

Since $(u, v) \in g(X) \times g(X)$, there exists a point $(\hat{u}, \hat{v}) \in X \times X$ such that

$$
u=g \hat{u}, \quad v=g \hat{v} .
$$

Thus, it follows from (2.28) and (2.29) that

$$
g \hat{u}=A(g \hat{u}, g \hat{v}), \quad g \hat{v}=A(g \hat{v}, g \hat{u}) .
$$

Also, from (2.23) and (2.30), we get

$$
g \hat{u}=F(\hat{u}, \hat{v}), \quad g \hat{v}=F(\hat{v}, \hat{u}) .
$$

Therefore, $(\hat{u}, \hat{v})$ is a coupled coincidence point of $F$ and $g$. This completes the proof.

Theorem 14 Let $(X, \preceq)$ be a partially ordered set and suppose that there exists a metric $d$ on $X$ such that $(X, d)$ is a metric space. Suppose that $F: X \times X \rightarrow X$ and $g: X \rightarrow X$ are self-mappings on $X$ such that $F$ has the mixed $g$-monotone property on $X$ such that there exist two elements $x_{0}, y_{0} \in X$ with $g\left(x_{0}\right) \preceq F\left(x_{0}, y_{0}\right)$ and $g\left(y_{0}\right) \succeq F\left(y_{0}, x_{0}\right)$. Suppose that there exists $\theta \in \Theta$ such that

$$
d(F(x, y), F(u, v)) \leq \theta(M(x, y, u, v))(M(x, y, u, v)),
$$

where

$$
M(x, y, u, v)=\frac{d(g x, F(x, y))+d(g y, F(y, x))+d(g u, F(u, v))+d(g v, F(v, u))}{4}
$$


for all $x, y, u, v \in X$ with $g x \geq g u$ and $g y \preceq g v$. Further suppose that $F(X \times X) \subseteq g(X)$ and $g(X)$ is a complete subspace of $X$. Also assume that either

(a) $F$ is continuous, or

(b) $X$ has the following properties:

(i) if $\left\{g\left(x_{n}\right)\right\} \subset X$ is a non-decreasing sequence with $g x_{n} \rightarrow g x$ in $g(X)$, then $g x_{n} \preceq g x$ for every $n$;

(ii) if $\left\{g\left(y_{n}\right)\right\} \subset X$ is a non-increasing sequence with $g y_{n} \rightarrow g y$ in $g(X)$, then $g y_{n} \succeq g y$ for every $n$.

Then there exist two elements $x, y \in X$ such that $F(x, y)=g(x)$ and $g y=F(y, x)$, that is, $F$ and $g$ have a coupled coincidence point $(x, y) \in X \times X$.

Proof Following similar arguments to those in Theorem 13 and using Theorem 2.2 of [15], we get the result.

Remark 15 Although Theorem 6 and Theorem 10 are an essential tool in the partially ordered metric spaces to claim the existence of coupled coincidence points of two mappings, some mappings do not have the commutative property. For example, see the following.

Example 16 Let $X=[0,1]$. Then $(X, \preceq)$ is a partially ordered set with the natural ordering of real numbers. Let $d(x, y)=x-y$ for all $x, y \in X$. Define mappings $F: X \times X \rightarrow X$ and $g: X \rightarrow X$ by $F(x, y)=1$ for all $(x, y) \in X \times X$ and $g(x)=x-1$ for each $x \in X$. Since $g(F(x, y))=$ $g(1)=0 \neq 1=F(g x, g y)$ for all $x, y \in X$, the mappings $F$ and $g$ do not satisfy the commutative condition. Hence, the above two theorems cannot be applied to this example. But, by a simple calculation, we see that $F(X \times X) \subseteq g(X), g$ and $F$ are continuous and $F$ has the mixed $g$-monotone property. Moreover, there exist $x_{0}=1$ and $y_{0}=3$ with $g(1)=0 \preceq 1=$ $F(1,3)$ and $g(3)=2 \succeq 1=F(3,1)$.

Therefore, it is very interesting to use Theorems 13 and 14 as another auxiliary tool to claim the existence of a coupled coincidence point.

Competing interests

The authors declare that they have no competing interests.

Authors' contributions

The main idea of this paper was proposed by JKK. JKK and SC prepared the manuscript initially and performed all the steps of the proof in this research. All authors read and approved the final manuscript.

\section{Author details}

${ }^{1}$ Department of Mathematics Education, Kyungnam University, Changwon, 631-701, Korea. ${ }^{2}$ Department of Mathematics, Khalsa College of Engineering \& Technology (Punjab Technical University), Ranjit Avenue, Amritsar, Punjab 143001, India.

\section{Acknowledgements}

This work was supported by the Kyungnam University Research Fund 2013. The authors are thankful to the referees for valuable suggestions.

Received: 1 April 2013 Accepted: 25 October 2013 Published: 22 Nov 2013

\section{References}

1. Ran, ACM, Reurings, MCB: A fixed point theorem in partially ordered sets and some applications to matrix equations. Proc. Am. Math. Soc. 132(5), 1435-1443 (2004)

2. Nieto, JJ, López, RR: Contractive mapping theorems in partially ordered sets and applications to ordinary differential equations. Order 22, 223-239 (2005)

3. Bhaskar, TG, Lakshmikantham, V: Fixed point theorems in partially ordered metric spaces and applications. Nonlinear Anal. 65, 1379-1393 (2006) 
4. Abbas, $M$, Sintunavarat, $W$, Kumam, $P$ : Coupled fixed point of generalized contractive mappings on partially ordered G-metric spaces. Fixed Point Theory Appl. 2012, 31 (2012)

5. Agarwal, RP, El-Gebeily, MA, O'Regan, D: Generalized contractions in partially ordered metric spaces. Appl. Anal. 87, 1-8 (2008)

6. Amini-Harandi, A, Emami, H: A fixed point theorem for contraction type maps in partially ordered metric spaces and application to ordinary differential equations. Nonlinear Anal. TMA 72(5), 2238-2242 (2010)

7. Caballero, J, Harjani, J, Sadarangani, K: Contractive-like mapping principles in ordered metric spaces and application to ordinary differential equations. Fixed Point Theory Appl. 2010, Article ID 916064 (2010). doi:10.1155/2010/916064

8. Chandok, S: Some common fixed point theorems for generalized $f$-weakly contractive mappings. J. Appl. Math. Inform. 29, 257-265 (2011)

9. Chandok, S: Some common fixed point theorems for generalized nonlinear contractive mappings. Comput. Math. Appl. 62, 3692-3699 (2011)

10. Chandok, S: Common fixed points, invariant approximation and generalized weak contractions. Int. J. Math. Math. Sci. 2012, 102980 (2012)

11. Chandok, S, Khan, MS, Rao, KPR: Some coupled common fixed point theorems for a pair of mappings satisfying a contractive condition of rational type without monotonicity. Int. J. Math. Anal. 7(9), 433-440 (2013)

12. Chandok, S, Kim, JK: Fixed point theorem in ordered metric spaces for generalized contractions mappings satisfying rational type expressions. Nonlinear Funct. Anal. Appl. 17, 301-306 (2012)

13. Chandok, S, Narang, TD, Taoudi, MA: Some common fixed point results in partially ordered metric spaces for generalized rational type contraction mappings. Vietnam J. Math. (2013). doi:10.1007/s10013-013-0024-4

14. Chandok, S, Sintunavarat, W, Kumam, P: Some coupled common fixed points for a pair of mappings in partially ordered G-metric spaces. Math. Sci. 7, 24 (2013). doi:10.1186/2251-7456-7-24

15. Choudhury, BS, Kundu, A: On coupled generalised Banach and Kannan type contractions. J. Nonlinear Sci. Appl. 5 , 259-270 (2012)

16. Geraghty, MA: On contractive mappings. Proc. Am. Math. Soc. 40, 604-608 (1973)

17. Haghi, RH, Rezapour, S, Shahzad, N: Some fixed point generalizations are not real generalizations. Nonlinear Anal. 74, 1799-1803 (2011). doi:10.1016/j.na.2010.10.052

18. Janos, L: On mappings contractive in the sense of Kannan. Proc. Am. Math. Soc. 61(1), 171-175 (1976)

19. Karapinar, E, Kumam, P, Sintunavarat, W: Coupled fixed point theorems in cone metric spaces with a $c$-distance and applications. Fixed Point Theory Appl. 2012, 194 (2012)

20. Lakshmikantham, V, Ciric, L: Coupled fixed point theorems for nonlinear contractions in partially ordered metric spaces. Nonlinear Anal. 70, 4341-4349 (2009)

21. Sintunavarat, W, Cho, YJ, Kumam, P: Coupled fixed point theorems for weak contraction mapping under F-invariant set. Abstr. Appl. Anal. 2012, Article ID 324874 (2012)

22. Sintunavarat, W, Kumam, P: Coupled best proximity point theorem in metric spaces. Fixed Point Theory Appl. 2012 93 (2012)

23. Sintunavarat, W, Kumam, P: Coupled coincidence and coupled common fixed point theorems in partially ordered metric spaces. Thai J. Math. 10(3), 551-563 (2012)

24. Sintunavarat, W, Cho, YJ, Kumam, P: Coupled fixed-point theorems for contraction mapping induced by cone ball-metric in partially ordered spaces. Fixed Point Theory Appl. 2012, 128 (2012)

25. Sintunavarat, W, Petrusel, A, Kumam, P: Common coupled fixed point theorems for $w^{*}$-compatible mappings without mixed monotone property. Rend. Circ. Mat. Palermo 61, 361-383 (2012)

26. Sintunavarat, W, Kumam, P, Cho, YJ: Coupled fixed point theorems for nonlinear contractions without mixed monotone property. Fixed Point Theory Appl. 2012, 170 (2012)

27. Sintunavarat, W, Radenovic, S, Golubovic, Z, Kumam, P: Coupled fixed point theorems for F-invariant set. Appl. Math. Inform. Sci. 7(1), 247-255 (2013)

10.1186/1687-1812-2013-307

Cite this article as: Kim and Chandok: Coupled common fixed point theorems for generalized nonlinear contraction mappings with the mixed monotone property in partially ordered metric spaces. Fixed Point Theory and Applications 2013, 2013:307

\section{Submit your manuscript to a SpringerOpen ${ }^{0}$ journal and benefit from:}

- Convenient online submission

- Rigorous peer review

- Immediate publication on acceptance

- Open access: articles freely available online

- High visibility within the field

- Retaining the copyright to your article

Submit your next manuscript at $\boldsymbol{~ s p r i n g e r o p e n . c o m ~}$ 